\title{
Solid-State Polymerization of Monomers Possessing Two Diphenylbutadiyne Moieties with Amido Groups to Form Ladder Polymers
}

\author{
Harumi Matsuo, Shuji OKada, Hachiro NAKAnishi, Hiro Matsuda, ${ }^{*}$ and Shigeru TAKARAgi** \\ Institute of Multidisciplinary Research for Advanced Materials, Tohoku University, 2-1-1 Katahira, \\ Aoba-ku, Sendai 980-8577, Japan \\ ${ }^{*}$ National Institute of Advanced Industrial Science and Technology, Central 5, 1-1-1 Higashi, \\ Tsukuba 305-8565, Japan \\ ${ }^{* *}$ Toda Kogyo Corp., 1-4 Meijishinkai, Otake, Hiroshima 739-0652, Japan
}

(Received May 23, 2002; Accepted September 20, 2002)

\begin{abstract}
Two series of monomers possessing two diphenylbutadiyne moieties connected by a methylene chain via amido groups, i.e., alkanedi\{3-[4-(3-nitrophenyl)butadynyl]anilide\} (N- $n$ ) and alkanedi\{3-[4-(3-alkanoylaminophenyl)butadiynyl]anilide $\}(m \mathbf{A}-n)$, were synthesized, and their solid-state polymerization behaviors and the polymer structures were investigated by various spectroscopic measurements and powder X-Ray diffractions. Although polymerization of $\mathbf{N}-n$ only proceeds in one of two diphenylbutadiyne moieties in a monomer to give single-chain polydiacetylenes, $m \mathbf{A}-n$ polymerized at both diphenylbutadiyne moieties to give double-chain polydiacetylenes. All the results suggest that two arrays of intermolecular hydrogen bonding formed between two diphenylbutadiyne moieties for $\mathbf{N}-n$ are not sufficient to fix the structure, and atomic movements during polymerization influence the polymerizable stack of the other remaining diphenylbutadiyne to disorder into non-polymerizable one. Meanwhile, $m \mathbf{A}-n$ can form four arrays of intermolecular hydrogen bonding on both sides of each diphenylbutadiyne moiety to fix it, and polydiactylene-based ladder polymers were successfully prepared from $m \mathbf{A}-n$.

KEY WORDS Polydiacetylene / Diphenylbutadiyne / Solid-State Polymerization / Hydrogen Bonding / Ladder Polymer /
\end{abstract}

Polydiacetylenes (PDAs) are obtained by solid-state 1,4-addition polymerization from the corresponding 1,3 -butadiyne monomers as crystalline $\pi$-conjugated polymers. ${ }^{1,2}$ Due to their $\pi$-conjugated polymer backbones, they have been expected to become functional materials for electronics and photonics. ${ }^{3-6}$ Especially, they have been reported to possess one of the largest third-order nonlinear optical (NLO) properties. ${ }^{6-12} \mathrm{We}$ have been investigating molecular design of PDAs for enhanced third-order NLO properties. Our molecular design of PDAs can be roughly classified in to the following two categories. The PDAs in the first category have $\pi$-conjugated substituents, which are directly attached to the backbone. The electronic structure of their $\pi$-conjugated polymer backbone must be perturbed by conjugation effect from substituents. ${ }^{13,14}$ Thus, we have been synthesizing a variety of PDAs having $\pi$-conjugation between polymer backbone and side chains, e.g., PDAs with aromatic substituents ${ }^{15-19}$ and acetylenic substituents, ${ }^{20-24}$ and confirmed enhancement of NLO properties. ${ }^{16-18}$ The PDAs in the other category contain design to increase $\pi$-conjugated backbone density. When two butadiyne moieties are incorporated in a fixed monomer molecular length and are fully polymerized, the PDAs obtained should have two PDA backbones in a monomer unit resulting in doubled backbone density compared with the single chain PDA. Thus, in order to prepare such ladder-type PDAs, monomers with two butadiyne moieties have been synthesized and their solid-state polymerization was studied. ${ }^{24-26}$ Especially, the monomers, in which two butadiyne moieties are connected by methylene chains with more than four carbons, were found to give fully polymerized ladder polymers. ${ }^{25}$ As a similar approach, preparation of a ladder polymer using $p$-xylylenediammonium disorbate as the bifunctional monomer in crystalline state was also reported recently. ${ }^{27}$

In the present study, we combined above two categories. Namely, several monomers possessing two diphenylbutadiyne moieties were synthesized and their solid-state polymerization was investigated. One of the prototype monomers was alkanedi\{3-[4-(3-nitrophenyl)butadynyl]anilide $\}$ derivatives ( $\mathbf{N}-n$ in Figure 1), which we previously synthesized and their solid-state polymerizability was reported although the polymer structure has not been clarified. ${ }^{28}$ These derivatives were designed referring to a pioneering work by Wegner. ${ }^{29} \mathrm{He}$ found that diphenylbutadiyne derivatives with nitro or amido groups at metaposition to the butadiyne moiety showed comparatively high solid-state polymerizability compared with those with nitro or amido groups at ortho- or paraposition. Among them, the crystallographic struc- 


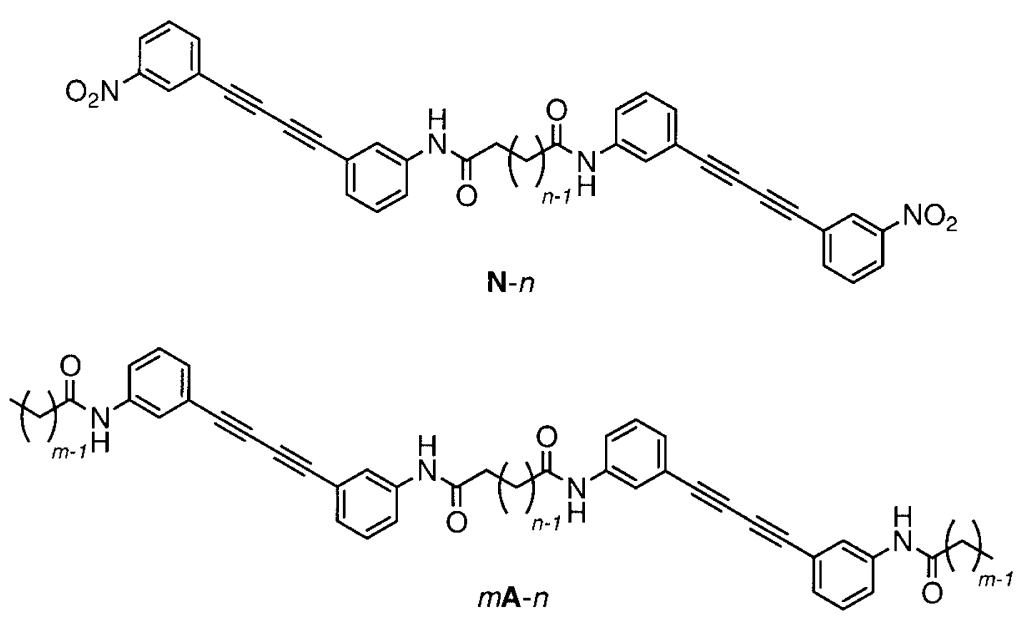

Figure 1. Chemical structures of investigated two kinds of monomers $\mathbf{N}-n$ and $m \mathbf{A}-n$ possessing two diphenylbutadiyne moieties.

ture of 1,4-bis(3-acetylaminophenyl)butadiyne was analyzed $^{30}$ and it was found that effective hydrogen bonding between adjacent monomers caused to form solidstate polymerizable stack, i.e., the stacking distance $d$ of monomers in the array and the angle $\theta$ between the DA rod and the stacking axis are around $5 \AA$ and $45^{\circ}$, respectively. ${ }^{2}$ In addition to $\mathbf{N}-n$, a new series of monomers ( $m \mathbf{A}-n$ in Figure 1) with increasing the number of the points to form hydrogen bonding were also prepared and structures of their polymers were analyzed.

\section{EXPERIMENTAL}

\section{Spectroscopy and X-Ray Diffraction}

UV-visible diffuse reflectance spectra in solid state were recorded for the powder samples dispersed in potassium bromide on a Jasco V-570 spectrometer attaching an ILN-472 integrating sphere. IR spectra were measured using a Shimadzu FT-IR- $8100 \mathrm{M}$ spectrometer. ${ }^{1} \mathrm{H}$ and ${ }^{13} \mathrm{C}$ NMR spectra in solution were obtained using Joel JMN-LA 400 or Bruker MSL300 spectrometer referring tetramethylsilane (TMS) as an internal standard. Solid-state ${ }^{13} \mathrm{C}$ NMR spectra were also recorded on a Bruker MSL-300 spectrometer with the cross polarization/magic angle spinning (CP/MAS) method. The methylene-carbon peak of external adamantane was set at $29.5 \mathrm{ppm}$ from TMS as a ${ }^{13} \mathrm{C}$ chemical shift in the solid state. The spinning sidebands were clearly distinguishable by using a TOSS (total suppression of spinning sidebands) pulse sequence. In order to identify the quaternary and mobile carbons, the pulse sequence for dipolar dephasing was also used. The powder X-Ray diffraction patterns were measured using a Mac Science M19XHF ${ }^{22}$-SRA diffractometer with a $\mathrm{Cu}-K \alpha$ radiation source.

\section{Synthesis of Monomers}

The monomers $\mathbf{N}-n$ and $m \mathbf{A}-n$ were prepared according to Figure 2, which includes palladium-catalyzed ethynylation of iodoarene ${ }^{31}$ and hetero-coupling ${ }^{32}$ and homo-coupling ${ }^{33}$ reactions of ethynyl derivatives. The detailed synthetic procedure is described below.

4-(3-Aminophenyl)-2-methyl-3-butyn-2-ol 1. Under a nitrogen atmosphere, 2-methyl-3-butyn-1-ol (11.52 g, $137 \mathrm{mmol}$ ), bis(triphenylphosphine)palladium(II) chloride $(1.60 \mathrm{~g}, \quad 2.28 \mathrm{mmol})$ and copper(I) chloride $(113 \mathrm{mg}, 1.14 \mathrm{mmol})$ were added to triethylamine solution $\left(500 \mathrm{~cm}^{3}\right)$ of 3-iodoaniline $(25.00 \mathrm{~g}, 114 \mathrm{mmol})$. The mixture was stirred for $15 \mathrm{~h}$ at ambient temperature. After removing the solvent by vacuum evaporation, the residue was purified by column chromatography (silica gel, chloroform:ethyl acetate $=$ $1: 1)$ to give $\mathbf{1}$ as colorless crystals in almost quantitative yield: ${ }^{1} \mathrm{H}$ NMR $\left(400 \mathrm{MHz}, \mathrm{CDCl}_{3}, \delta\right) 1.60(6 \mathrm{H}$, s), $2.04(1 \mathrm{H}, \mathrm{s}), 3.66(2 \mathrm{H}, \mathrm{s}), 6.63(1 \mathrm{H}, \mathrm{d}, J=7.8 \mathrm{~Hz})$, $6.74(1 \mathrm{H}, \mathrm{s}), 6.82(1 \mathrm{H}, \mathrm{d}, J=7.8 \mathrm{~Hz}), 7.08(1 \mathrm{H}, \mathrm{dd}$, $J=7.8,7.8 \mathrm{~Hz}) ;{ }^{13} \mathrm{C} \mathrm{NMR}\left(100 \mathrm{MHz}, \mathrm{CDCl}_{3}, \delta\right) 31.5$, $65.6,82.3,93.1,115.3,117.9,122.0,123.4,129.2$, 146.2 .

3-Ethynylaniline 2. Alcohol $1(20.00 \mathrm{~g}, 114 \mathrm{mmol})$ was dissolved in $500 \mathrm{~cm}^{3}$ of toluene. To the solution, powdered potassium hydroxide $(6.40 \mathrm{~g}, 114 \mathrm{mmol})$ was added and the mixture was heated at $80^{\circ} \mathrm{C}$ for $18 \mathrm{~h}$. After cooling to ambient temperature, the reaction mixture was filtered and the solvent in the filtrate was evaporated. The residue was purified by column chromatography (silica gel, chloroform) resulting in $\mathbf{2}$ as pale yellow oil $(12.80 \mathrm{~g}, 96 \%) ;{ }^{1} \mathrm{H}$ NMR $\left(400 \mathrm{MHz}, \mathrm{CDCl}_{3}, \delta\right)$ $3.02(1 \mathrm{H}, \mathrm{s}), 3.56(2 \mathrm{H}, \mathrm{s}), 6.63(1 \mathrm{H}, \mathrm{d}, J=7.8 \mathrm{~Hz})$, $6.78(1 \mathrm{H}, \mathrm{s}), 6.89(1 \mathrm{H}, \mathrm{d}, J=7.8 \mathrm{~Hz}), 7.08(1 \mathrm{H}, \mathrm{dd}$, $J=7.8,7.8 \mathrm{~Hz}) ;{ }^{13} \mathrm{C} \mathrm{NMR}\left(100 \mathrm{MHz}, \mathrm{CDCl}_{3}, \delta\right) 76.5$, $83.9,115.7,118.2,122.3,122.6,129.2,146.2$. 

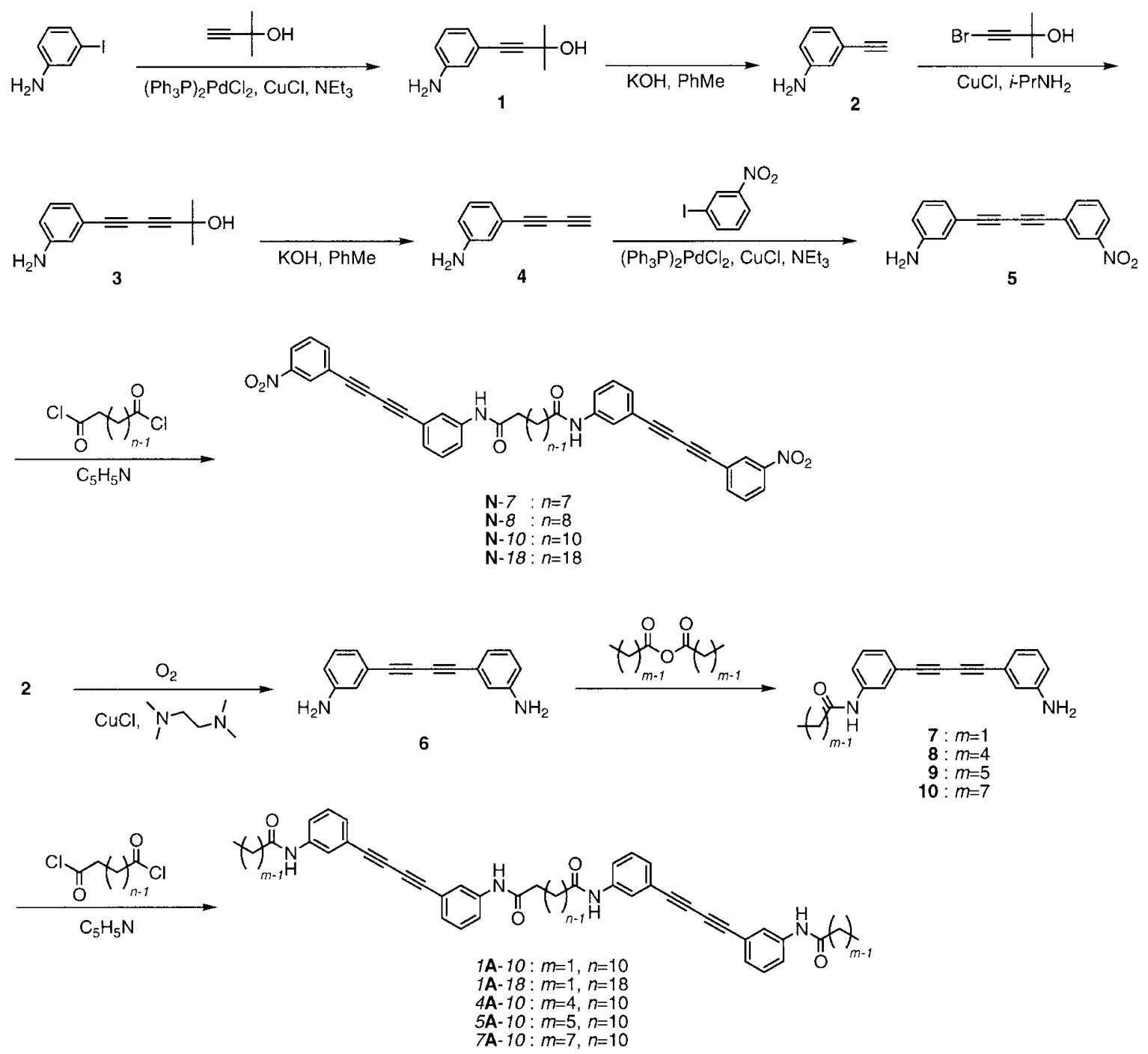

Figure 2. Synthetic schemes for $\mathbf{N}-n$ and $m \mathbf{A}-n$.

6-(3-Aminophenyl)-2-methyl-3,5-hexadiyn-2-ol 3.

To the tetrahydrofuran (THF) solution $\left(40 \mathrm{~cm}^{3}\right)$ of $2(5.22 \mathrm{~g}, 44.5 \mathrm{mmol})$, copper(I) chloride $(441 \mathrm{mg}$, $4.45 \mathrm{mmol})$ and 2 -aminopropane $\left(40 \mathrm{~cm}^{3}\right)$ were added. To this orange mixture, THF solution $\left(40 \mathrm{~cm}^{3}\right)$ of 4bromo-2-methyl-3-butyn-1-ol ( $8.72 \mathrm{~g}, 53.5 \mathrm{mmol})$ was added dropwise at ambient temperature for $2.5 \mathrm{~h}$. When the color of the mixture became green, appropriate amount of hydroxylamine hydrochloride was added till the color turned to orange. After stirring for additional $12 \mathrm{~h}$, the solvent of the mixture was evaporated. To the residue, water was added and it was extracted with chloroform. The organic layer was dried over anhydrous sodium sulfate and filtered. The solvent of the filtrate was evaporated, and the residue was purified by column chromatography (silica gel, chloroform:ethyl acetate $=3: 1)$ to give 3 as pale yellow oil $(7.10 \mathrm{~g}$, $80 \%) ;{ }^{1} \mathrm{H}$ NMR $\left(400 \mathrm{MHz}, \mathrm{CDCl}_{3}, \delta\right) 1.57(6 \mathrm{H}, \mathrm{s})$, $2.05(1 \mathrm{H}, \mathrm{s}), 3.70(2 \mathrm{H}, \mathrm{s}), 6.68(1 \mathrm{H}, \mathrm{d}, J=7.8 \mathrm{~Hz})$, $6.79(1 \mathrm{H}, \mathrm{s}), 6.89(1 \mathrm{H}, \mathrm{d}, J=7.8 \mathrm{~Hz}), 7.10(1 \mathrm{H}, \mathrm{dd}$, $J=7.8,7.8 \mathrm{~Hz})$.
1-(3-Aminophenyl)-4-(3-nitrophenyl)butadiyne 5 via 1-(3-Aminophenyl)butadiyne 4. Alcohol 3 (4.38 g, $22 \mathrm{mmol}$ ) was dissolved in $300 \mathrm{~cm}^{3}$ of toluene. To the solution, powdered potassium hydroxide $(1.50 \mathrm{~g}$, $27 \mathrm{mmol}$ ) was added and the mixture was heated at $80^{\circ} \mathrm{C}$ for $18 \mathrm{~h}$. After cooling to ambient temperature, the reaction mixture was filtered and the solvent in the filtrate was evaporated till the solution volume became $50 \mathrm{~cm}^{3}$. Since 4 is very reactive to give a black polymer, 4 was not isolated and the concentrated toluene solution was used in the next step. To the mixture of the above toluene solution, 3-iodonitrobenzene $(5.30 \mathrm{~g}$, $21 \mathrm{mmol}$ ), bis(triphenylphosphine)palladium(II) chloride $(300 \mathrm{mg}, 0.43 \mathrm{mmol})$ and triethylamine $\left(300 \mathrm{~cm}^{3}\right)$, copper(I) chloride (30 mg, $0.30 \mathrm{mmol}$ ) were added, and the mixture was stirred under a nitrogen atmosphere at ambient temperature for $14 \mathrm{~h}$. The solvent of the reaction mixture was evaporated. The residue was purified by column chromatography (silica gel, chloroform) resulting in 5 as pale yellow crystals $(3.70 \mathrm{~g}, 64 \%$ from 3); ${ }^{1} \mathrm{H}$ NMR (400 MHz, $\left.\mathrm{CDCl}_{3}, \delta\right) 3.73(2 \mathrm{H}, \mathrm{s})$, 
$6.72(1 \mathrm{H}, \mathrm{d}, J=8.1 \mathrm{~Hz}), 6.85(1 \mathrm{H}, \mathrm{s}), 6.96(1 \mathrm{H}, \mathrm{d}$, $J=7.6 \mathrm{~Hz}), 7.14(1 \mathrm{H}, \mathrm{dd}, J=7.6,8.1 \mathrm{~Hz}), 7.53(1 \mathrm{H}$, $\mathrm{dd}, J=7.8,8.2 \mathrm{~Hz}), 7.81(1 \mathrm{H}, \mathrm{d}, 7.8 \mathrm{~Hz}), 8.21(1 \mathrm{H}, \mathrm{d}$, $8.2 \mathrm{~Hz}), 8.36(1 \mathrm{H}, \mathrm{s}) ;{ }^{13} \mathrm{C}$ NMR $\left(100 \mathrm{MHz}\right.$, DMSO- $d_{6}$, $\left.100^{\circ} \mathrm{C}, \delta\right) 72.5,76.6,78.3,83.5,116.7,118.4,121.8$, $123.1,123.7,123.9,127.2,129.47,129.51,138.0$, 146.4, 148.1.

Icosanedi\{3-[4-(3-nitrophenyl)butadiynyl] anilide\} $\mathbf{N}$ 18. To the toluene solution $\left(10 \mathrm{~cm}^{3}\right)$ of icosanedioyl chloride $(380 \mathrm{mg}, 1 \mathrm{mmol})$, pyridine solution $\left(5 \mathrm{~cm}^{3}\right)$ of 5 (525 mg, $2 \mathrm{mmol}$ ) was added dropwise under a nitrogen atmosphere at ambient temperature. After stirring for $6.5 \mathrm{~h}, 150 \mathrm{~cm}^{3}$ of methanol was added to the reaction mixture and precipitated solid was filtered off. This solid was recrystallized from chloroform-THF to give $\mathbf{N}-18$ as a yellow powder (430 mg, $52 \%$ ); mp $170{ }^{\circ} \mathrm{C} ;{ }^{1} \mathrm{H}$ NMR $\left(300 \mathrm{MHz}, \mathrm{DMSO}-d_{6}, \delta\right) 1.25(28 \mathrm{H}$, $\mathrm{m}), 1.61(4 \mathrm{H}, \mathrm{m}), 2.31(4 \mathrm{H}, \mathrm{t}, J=7.3 \mathrm{~Hz}), 7.26(2 \mathrm{H}$, d, $J=7.8 \mathrm{~Hz}), 7.35(2 \mathrm{H}, \mathrm{dd}, J=7.8,7.4 \mathrm{~Hz}), 7.62$ $(2 \mathrm{H}, \mathrm{d}, J=7.4 \mathrm{~Hz}), 7.72(2 \mathrm{H}, \mathrm{dd}, J=7.8,8.1 \mathrm{~Hz})$, $7.89(2 \mathrm{H}, \mathrm{s}), 8.01(2 \mathrm{H}, \mathrm{d}, J=7.8 \mathrm{~Hz}), 8.26(2 \mathrm{H}, \mathrm{d}$, $J=8.1 \mathrm{~Hz}), 8.34(2 \mathrm{H}, \mathrm{s}), 9.75(2 \mathrm{H}, \mathrm{s}) ;{ }^{13} \mathrm{C} \mathrm{NMR}$ $\left(100 \mathrm{MHz}, \mathrm{DMSO}-d_{6}, 100^{\circ} \mathrm{C}, \delta\right) 25.0,28.4,28.5$, $36.4,72.7,75.3,79.3,82.9,120.1,120.9,122.1,122.2$, 124.6, 126.8, 127.0, 129.5, 130.6, 138.6, 139.7, 147.9, 171.7; IR (KBr) 3287, 3084, 2919, 2851, 2222, 1655, $1530,1352 \mathrm{~cm}^{-1}$; Found: C, 74.92; H, 6.62; N, 6.40\%. Calcd for $\mathrm{C}_{50} \mathrm{H}_{50} \mathrm{~N}_{4} \mathrm{O}_{6}$ : C, 74.79: $\mathrm{H}, 6.28: \mathrm{N}, 6.98 \%$.

Nonanedi\{3-[4-(3-nitrophenyl)butadiynyl]anilide\} N-7 was prepared by the similar procedure to the synthesis of $\mathbf{N}-18$ using azelaoyl chloride instead of icosanedioyl chloride. To the reaction mixture, water was added and it was extracted with ethyl acetate. The organic layer was dried over anhydrous sodium sulfate and filtered. The solvent of the filtrate was evaporated, and the residual solid was recrystallized from ethyl acetate to give $\mathbf{N}-7$ as a yellow powder $(60 \%)$; mp $149^{\circ} \mathrm{C}$. By the similar procedure to the synthesis of $\mathbf{N}-7, \mathbf{N}-8$ was prepared using sebacoyl chloride instead of azelaoyl chloride to give $\mathbf{N}-8$ as a yellow powder (44\%); mp $178{ }^{\circ} \mathrm{C}$. Also, $\mathbf{N}-10$ was prepared using dodecanedioyl chloride. After recrystallization from chloroform-THF, $\mathbf{N}-10$ was obtained as a yellow powder $(69 \%)$; mp $170{ }^{\circ} \mathrm{C}$.

1,4-Bis(3-aminophenyl)butadiyne 6 . To the mixture of copper(I) chloride (1.49 g, $15 \mathrm{mmol}), N, N, N^{\prime}$,$N^{\prime}$-tetramethylethylenediamine $(1.74 \mathrm{~g}, 15 \mathrm{mmol})$ and acetone $\left(500 \mathrm{~cm}^{3}\right), 2(12.89 \mathrm{~g}, 110 \mathrm{mmol})$ was added and stirred. Oxygen was bubbled into the mixture for $4 \mathrm{~h}$. After solvent evaporation of the reaction mixture, water was added and it was extracted with chloroform. The chloroform layer was dried over anhydrous sodium sulfate and filtered. The solvent in the filtrate was evap- orated and the residual solid was recrystallized from toluene to give 6 as a pale yellow solid $(6.60 \mathrm{~g}, 52 \%)$; ${ }^{1} \mathrm{H}$ NMR $\left(400 \mathrm{MHz}, \mathrm{CDCl}_{3}, \delta\right) 3.70(4 \mathrm{H}, \mathrm{s}), 6.68(2 \mathrm{H}$, $\mathrm{d}, J=7.9 \mathrm{~Hz}), 6.82(2 \mathrm{H}, \mathrm{s}), 6.93(2 \mathrm{H}, \mathrm{d}, J=7.8 \mathrm{~Hz})$, $7.11(2 \mathrm{H}, \mathrm{dd}, J=7.8,7.9 \mathrm{~Hz}) ;{ }^{13} \mathrm{C}$ NMR $(100 \mathrm{MHz}$, $\left.\mathrm{CDCl}_{3}, \delta\right) 73.3,81.6,116.2,118.4,122.5,122.9,129.3$, 146.3 .

\section{1-(3-Aminophenyl)-4-(3-acetylaminophenyl)buta-}

diyne 7. Under nitrogen atmosphere, acetic anhydride ( $880 \mathrm{mg}, 8.6 \mathrm{mmol})$ was added to $6(3.95 \mathrm{~g}, 17 \mathrm{mmol})$ in THF $\left(100 \mathrm{~cm}^{3}\right)$ and the mixture was stirred at ambient temperature for $1.5 \mathrm{~h}$. Acetic anhydride ( $880 \mathrm{mg}$ ) was again added to it and it was further stirred at ambient temperature for $2 \mathrm{~h}$. Water was added to the reaction mixture and it was extracted with chloroform. The chloroform layer was dried over anhydrous sodium sulfate and filtered. After removal of solvent in the filtrate, the residue was purified by column chromatography (silica gel, chloroform:ethyl acetate $=3: 1$ ). Since the solubility of the residue to the eluent was not so large at ambient temperature, the eluent was heated. The first portion contained recovered $6(829 \mathrm{mg}, 21 \%)$. From the second portion, 7 was obtained as a pale yellow solid (2.15 g, 46\%); ${ }^{1} \mathrm{H}$ NMR $\left(400 \mathrm{MHz}, \mathrm{DMSO}-d_{6}, \delta\right) 2.05(3 \mathrm{H}, \mathrm{s}), 5.33(2 \mathrm{H}, \mathrm{s})$, $6.65(1 \mathrm{H}, \mathrm{d}, J=8.3 \mathrm{~Hz}), 6.70(1 \mathrm{H}, \mathrm{d}, J=7.7 \mathrm{~Hz}), 6.71$ $(1 \mathrm{H}, \mathrm{s}), 7.05(1 \mathrm{H}, \mathrm{dd}, J=7.7,8.3 \mathrm{~Hz}), 7.25(1 \mathrm{H}, \mathrm{d}$, $J=7.6 \mathrm{~Hz}), 7.34(1 \mathrm{H}, \mathrm{dd}, J=7.6,8.0 \mathrm{~Hz}), 7.57(1 \mathrm{H}$, $\mathrm{d}, J=8.0 \mathrm{~Hz}), 7.85(1 \mathrm{H}, \mathrm{s}), 10.09(1 \mathrm{H}, \mathrm{s})$. The third portion gave 1,4-bis(3-acetylaminophenyl)butadiyne (1.16 g, 22\%).

1-(3-Aminophenyl)-4-(3-pentanoylaminophenyl)butadiyne 8. To $6(2.00 \mathrm{~g}, 8.61 \mathrm{mmol})$ in THF $\left(20 \mathrm{~cm}^{3}\right)$, $n$-valeric anhydride $(1.90 \mathrm{~g}, 10.2 \mathrm{mmol})$ was added three times at intervals of $3.5 \mathrm{~h}$ under nitrogen atmosphere at ambient temperature. After addition has completed, the reaction mixture was further stirred for $3 \mathrm{~h}$ and solvent was evaporated. Water was added to the reaction mixture and it was extracted with chloroform. The chloroform layer was dried over anhydrous sodium sulfate and filtered. After removal of solvent in the filtrate, the residue was purified by column chromatography with hot eluent (silica gel, chloroform:ethyl acetate $=3: 1$ ). The first portion gave 1,4-bis(3-pentanoylaminophenyl)butadiyne ( $0.11 \mathrm{~g}, 3 \%)$. From the second portion, 8 was obtained as a pale yellow solid (1.00 g, 38\%). The starting material 6 was also recovered.

The procedure for the preparation of 1-(3aminophenyl)-4-(3-hexanoylaminophenyl)butadiyne $\mathbf{9}$ was similar to that of $\mathbf{8}$ using $n$-caproic anhydride instead of $n$-valeric anhydride. After purification by column chromatography, 9 was obtained as a pale 
yellow solid (44\%). Also, 1-(3-aminophenyl)-4-(3octanoylaminophenyl)butadiyne $\mathbf{1 0}$ was prepared using $n$-caprylic anhydride instead of $n$-valeric anhydride. After purification by column chromatography, $\mathbf{1 0}$ was obtained as a pale yellow solid (19\%).

Dodecanedi\{3-[4-(3-octanoylaminophenyl)butadiynyl]anilide\} 7A-10. To the solution of $\mathbf{1 0}(0.54 \mathrm{~g}$, $0.51 \mathrm{mmol})$, pyridine $\left(10 \mathrm{~cm}^{3}\right)$ and toluene $\left(50 \mathrm{~cm}^{3}\right)$, dodecandioyl chloride $(0.10 \mathrm{~g}, 0.39 \mathrm{mmol})$ was added dropwise under nitrogen atmosphere at ambient temperature. After stirring for $3 \mathrm{~h}, 200 \mathrm{~cm}^{3}$ of methanol was added to the reaction mixture, and precipitated solid was filtered off. The solid portion was recrystallized from $N, N$-dimethylformamide (DMF) to give $7 \mathbf{A}-10$ as colorless powder $(0.40 \mathrm{~g}, 59 \%) ; \mathrm{mp}$ $259{ }^{\circ} \mathrm{C}$; ${ }^{1} \mathrm{H}$ NMR $\left(300 \mathrm{MHz}\right.$, DMSO- $\left.d_{6}, 100{ }^{\circ} \mathrm{C}, \delta\right)$ $0.88(6 \mathrm{H}, \mathrm{t}, J=7.0 \mathrm{~Hz}), 1.31(28 \mathrm{H}, \mathrm{m}), 1.62(8 \mathrm{H}, \mathrm{tt}$, $J=6.9,7.3 \mathrm{~Hz}), 2.31(8 \mathrm{H}, \mathrm{t}, J=7.3 \mathrm{~Hz}), 7.23(4 \mathrm{H}, \mathrm{d}$, $J=7.7 \mathrm{~Hz}), 7.33(4 \mathrm{H}, \mathrm{dd}, J=7.7,7.7 \mathrm{~Hz}), 7.61(4 \mathrm{H}$, $\mathrm{d}, J=7.7 \mathrm{~Hz}), 7.84(4 \mathrm{H}, \mathrm{s}), 9.66(4 \mathrm{H}, \mathrm{s}) ;{ }^{13} \mathrm{C} \mathrm{NMR}$ $\left(75 \mathrm{MHz}, \mathrm{DMSO}-d_{6}, 100^{\circ} \mathrm{C}, \delta\right) 21.5,24.6,27.9,28.3$, 28.4, 30.7, 36.2, 72.9, 81.6, 120.5, 120.6, 122.4, 126.5, 128.8, 139.4, 171.2; IR (KBr) 3287, 2921, 2853, 1655, 1582, $1534 \mathrm{~cm}^{-1}$; Found: C, 78.99; H, 7.80; N, 5.74\%. Calcd for $\mathrm{C}_{60} \mathrm{H}_{70} \mathrm{~N}_{4} \mathrm{O}_{4}$ : C, 79.09: $\mathrm{H}, 7.74$ : N, 6.15\%.

The procedures for the preparation of dodecanedi\{3-[4-(3-acetylaminophenyl)butadiynyl]anilide\}

1A-10, dodecanedi\{3-[4-(3-pentanoylaminophenyl)butadiynyl]anilide $\} \quad 4 \mathbf{A}-10$ and dodecanedi $\{3-[4-(3-$ hexanoylaminophenyl)butadiynyl]anilide $3 \mathrm{~A}-10$ were similar to those of $7 \boldsymbol{A}-10$ using $\mathbf{7}, \mathbf{8}$, and $\mathbf{9}$, respectively, instead of 10. The yields were $37 \%, 38 \%$, and $82 \%$, respectively. Icosanedi\{3-[4-(3-acetylaminophenyl)butadiynyl]anilide 1 A -18 was prepared in the similar way to $7 \boldsymbol{A}-10$ using $\mathbf{7}$ instead of $\mathbf{1 0}$ and icosanedioyl chloride instead of dodecanedioyl chloride, and the yield was $37 \%$. These were obtained as colorless powders. Melting points of $1 \mathbf{A}-10,4 \mathbf{A}-10,5 \mathbf{A}-10$, and $1 \mathrm{~A}-18$ are $272{ }^{\circ} \mathrm{C}, 265^{\circ} \mathrm{C}, 263^{\circ} \mathrm{C}$, and $238^{\circ} \mathrm{C}$, respectively.

\section{Solid-State Polymerization}

Polymerizability of the monomers were first evaluated by color change into blue stimulated by UV irradiation at $254 \mathrm{~nm}$ from a 4-W lamp (UVG-11, UVP). For $\gamma$-ray induced polymerization, the powder samples were put into glass tubes, evacuated and sealed. The source and dose rate of $\gamma$-ray were ${ }^{60} \mathrm{Co}$ and about $10 \mathrm{kGy} \mathrm{h}^{-1}$, respectively. Polymer yield was gravimetrically evaluated by extracting monomers. Solvents used for extracting monomers were hot ethyl acetate for $\mathbf{N}-8$, hot THF for $\mathbf{N}-10$, and $\mathbf{N}-18$ and hot DMF for $m \mathbf{A}-n$.

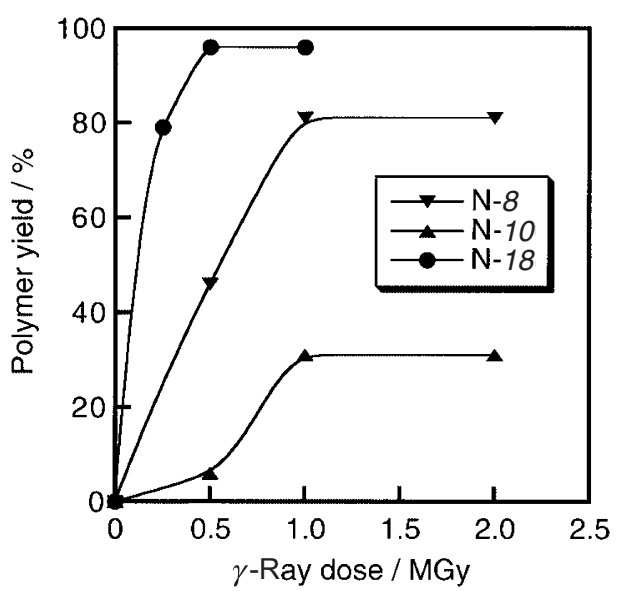

Figure 3. Polymer yield curves for $\mathbf{N}-n$ depending on $\gamma$-ray dose.

\section{RESULTS AND DISCUSSION}

\section{$N$ - $n$ Derivatives}

Among the monomers synthesized in $\mathbf{N}-n$ series, $\mathbf{N}-$ 7 shows no solid-state polymerizability, although $\mathbf{N}-8$, $\mathbf{N}-10$, and $\mathbf{N}-18$ could be polymerized in solid state by UV irradiation. This result coincided with the previous report, in which the compounds with odd $n$ were found to have less solid-state polymerizability than the compounds with even $n \cdot{ }^{27}$ Such critically different polymerization behavior depending on whether the methylene number is odd or even has been reported even for other diacetylene derivatives with urethane groups. ${ }^{33}$ In $\mathbf{N}-n$, the wavenumber for the $\mathrm{C}=\mathrm{O}$ stretching vibration $\left(v_{\mathrm{C}=0}\right)$ of $\mathbf{N}-8, \mathbf{N}-10$, and $\mathbf{N}-18$ was found at $1655 \mathrm{~cm}^{-1}$, while that of $\mathbf{N}-7$ was $5-\mathrm{cm}^{-1}$ larger. This indicates that intermolecular hydrogen bonding between amido groups of adjacent monomers of non-polymerizable $\mathbf{N}$ $n$ with odd $n$ is weaker than that of polymerizable $\mathbf{N}-n$ with even $n$. Stronger intermolecular hydrogen bonding may be favorable to form polymerizable stack in this series of compounds. Figure 3 shows polymer yield curves depending on $\gamma$-ray dosage. All yields were saturated at certain dosages, and final polymer yields for $\mathbf{N}-8, \mathbf{N}-10$, and $\mathbf{N}-18$ were about $80 \%$, about $30 \%$ and more than $95 \%$, respectively. The maximum polymer yield for diphenylbutadiyne derivatives with amido groups reported by Wegner was only $25 \%{ }^{29}$ and much higher polymer yield was achieved for $\mathbf{N}-n$ derivatives. The long methylene (or alkyl) chain attached to butadiyne derivatives are known to often improve polymer yields ${ }^{16,35,36}$ due to its polymerizable-stack formability and its flexibility necessary for molecular motion during polymerization. $\mathbf{N}-n$ derivatives are not the exception.

Figure 4 displays the UV-visible diffuse reflectance 


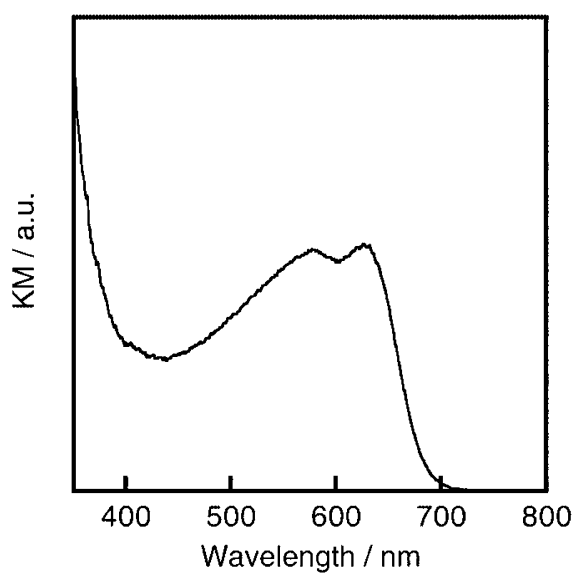

Figure 4. UV-visible diffuse reflectance spectrum of the polymer from $\mathbf{N}-18$.

spectrum for $\mathbf{N}-18$ as a representative example. Spectra for the polymers obtained from $\mathbf{N}-8$ and $\mathbf{N}-10$ were almost the same. The maximum wavelengths for the excitonic band and its phonon sideband were observed at about $630 \mathrm{~nm}$ and about $570 \mathrm{~nm}$, respectively, which were typical for the ordered blue-phase PDAs. However, in IR spectra, we found that absorbance of the $\mathrm{C} \equiv \mathrm{C}$ stretching vibration $\left(v_{\mathrm{C} \equiv \mathrm{C}}\right)$ at $2224 \mathrm{~cm}^{-1}$ of the polymerized samples did not disappear. When all the butadiyne moieties have been polymerized, $\mathrm{C} \equiv \mathrm{C}$ bonds were incorporated in polymer backbones and $v_{\mathrm{C} \equiv \mathrm{C}}$ band was expected to be vanished due to a symmetrical environment of $\mathrm{C} \equiv \mathrm{C}$ bonds in the polymer backbones. From the peak intensities of the $v_{\mathrm{C} \equiv \mathrm{C}}$ band of the polymers, the remaining butadiyne moieties in the polymers compared with the corresponding monomers were estimated to be around $55 \%$ for the three compounds. Namely, about half of the butadiyne moieties still existed even after polymerization, indicating that only one of two butadiyne moieties per monomer was taken part in the solid-state polymerization. This fact was further confirmed by solid-state ${ }^{13} \mathrm{C}$ NMR spectra of the polymerized samples. The CP/MAS spectra of $\mathrm{N}-18$ are shown in Figure 5 as a typical ones, and similar spectra were obtained for other two compounds. Even in the spectrum of the sample with 1-MGy $\gamma$-ray dose (Figure $5 \mathrm{c}$ ), acetylenic ${ }^{13} \mathrm{C}$ peaks at $74 \mathrm{ppm}$ and $81 \mathrm{ppm}$ for the monomer clearly remained irrespective of appearance of the acetylenic peak for the PDA backbone at $103 \mathrm{ppm}$. Unfortunately, the olefinic peak for the polymer backbone was hard to distinguish from overlapped aromatic peaks. From these spectroscopic analysis, polymerized $\mathbf{N}-n$ derivatives were concluded to give a single-chain linear PDA. In the powder X-Ray diffraction experiments, we found that there were a little peak intensity reduction and peak broadening especially for peaks at small angles corresponding to the long-period spacings, as shown in Figure 6 for $\mathbf{N}-18$ as

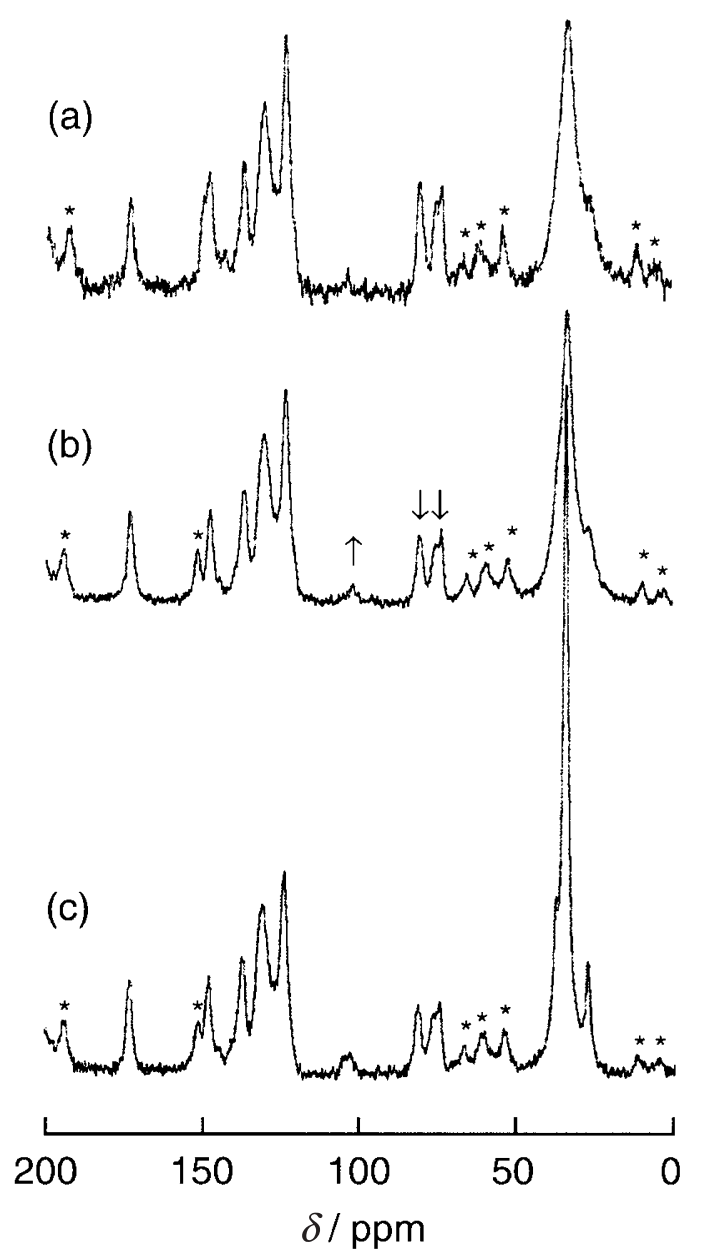

Figure 5. ${ }^{13} \mathrm{C} \mathrm{CP} / \mathrm{MAS}$ spectra of N-18: (a) Monomer, (b) after 250 -MGy $\gamma$-ray dose and (c) after 1-MGy $\gamma$-ray dose. Asterisks indicate spinning sidebands.

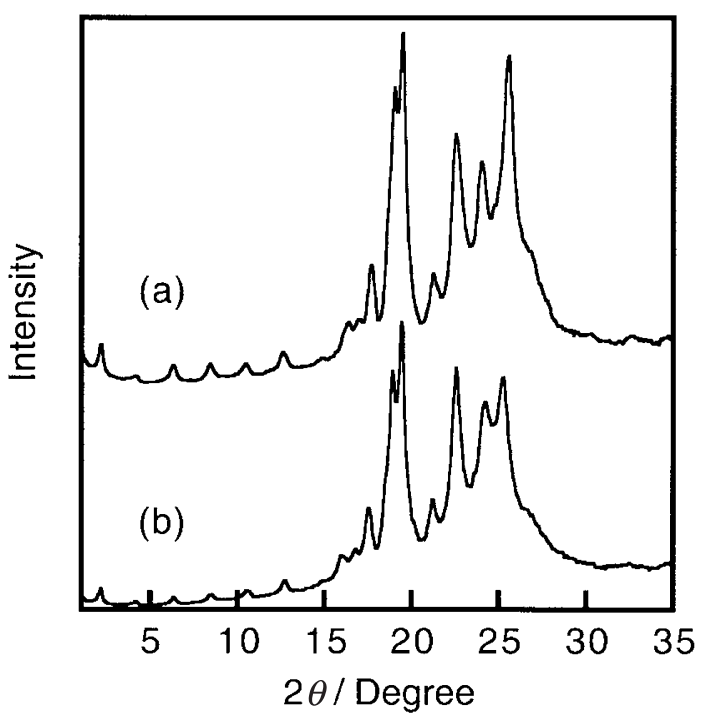

Figure 6. Powder X-Ray diffraction patterns of N-18: (a) Monomer and (b) polymer obtained after 1-MGy $\gamma$-ray dose.

a typical example.

The reason why only one of two butadiyne moieties in the monomer could be polymerized is not due to an asymmetric molecular structure of the monomer 
in crystals. Because ${ }^{13} \mathrm{C}$ peaks were not split indicating the same environment of carbons for all substituents, and all the butadiyne moieties have chances equally to be polymerized. From this consideration, the non-polymerized butadiyne moieties seems to be produced after starting polymerization. Namely, the movement of the atom positions related to the solidstate polymerization around a butadiyne moiety affects to the arrangement of the butadiyne moieties, which are to be polymerized, within the same monomer or in the monomer in the adjacent column. Slight degradation of the powder X-Ray diffraction patterns may support this fact. In order to fix the arrangement of the butadiyne moieties in a polymerizable stack, fixation around the polymerizable portions seemed to be effective, for example, by using strong intermolecular interaction. Although $\mathbf{N}-n$ monomers have two amido groups per monomer, which form two arrays of intermolecular hydrogen bonding sequences in a column, they were insufficient to maintain the polymerizable stack after starting solid-state polymerization. Thus, we synthesized $m \mathbf{A}-n$ monomers, which have two more amido groups by substituting nitro groups of $\mathbf{N}$ $n$ into amido groups. For $m \mathbf{A}-n$, the polymerizable stacks were expected to be kept by four arrays of intermolecular hydrogen bonding sequences, which fixed diphenylbutadiyne moieties from both side.

\section{$m \boldsymbol{A}-n$ Derivatives}

The synthesized compounds as $m \mathbf{A}-n$ monomers had even number of $n$, i.e., $n=10$ or $n=18$, based on the results on polymerizability obtained for $\mathbf{N}-n$. According to expectation, all the $m \mathbf{A}-n$ monomers prepared could be reacted to be blue-colored polymers upon UV irradiation. These monomers exhibit $v_{\mathrm{C}=\mathrm{O}}$ at $1655 \mathrm{~cm}^{-1}$, which is the same as polymerizable $\mathbf{N}$ $n$ with even $n$. Polymer yields for $m \mathbf{A}-n$ depending on $\gamma$-ray dose are presented in Figure 7. Yields of all these monomers reached more than $80 \%$ only by $250-\mathrm{kGy} \gamma$ ray dose, and initial reaction rate seemed to be faster than $\mathbf{N}-18$, which is the most polymerizable $\mathbf{N}-n$ in this study. Final yields of these polymers were almost quantitative.

Their polymer structures were investigated by solidstate ${ }^{13} \mathrm{C}$ NMR spectroscopy. As a typical example, $\mathrm{CP} / \mathrm{MAS}$ spectra of $7 \mathbf{A}-10$ are shown in Figure 8. As $\gamma$-ray dose increased, the intensities of two peaks at $74 \mathrm{ppm}$ and $81 \mathrm{ppm}$ corresponding to acetylenic carbons of the butadiyne moieties gradually diminished and a new peak at $103 \mathrm{ppm}$ corresponding to acetylenic carbons in the PDA backbones obviously developed. Furthermore, in the region around $140 \mathrm{ppm}$, where a

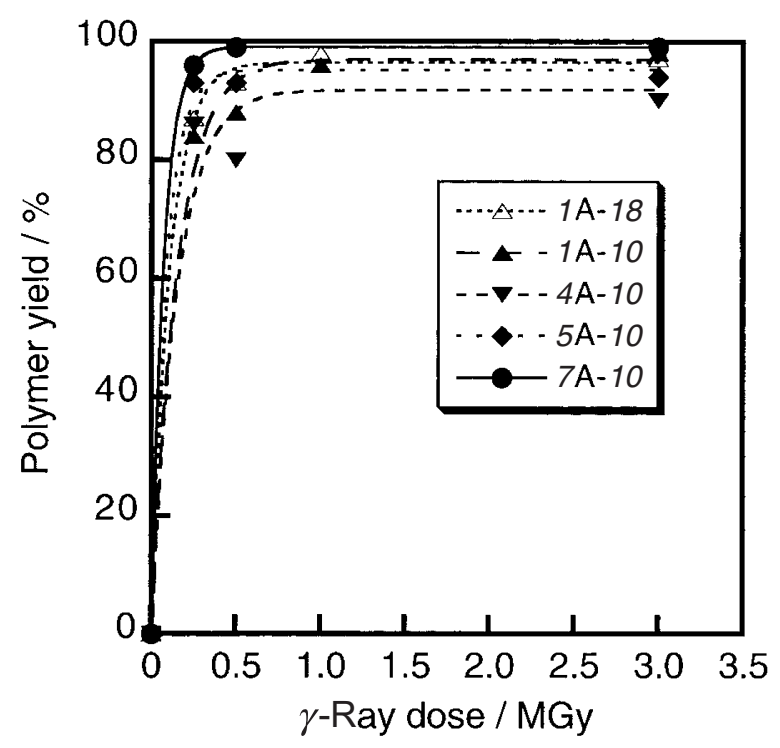

Figure 7. Polymer yield curves for $m \mathbf{A}-n$ depending on $\gamma$-ray dose.

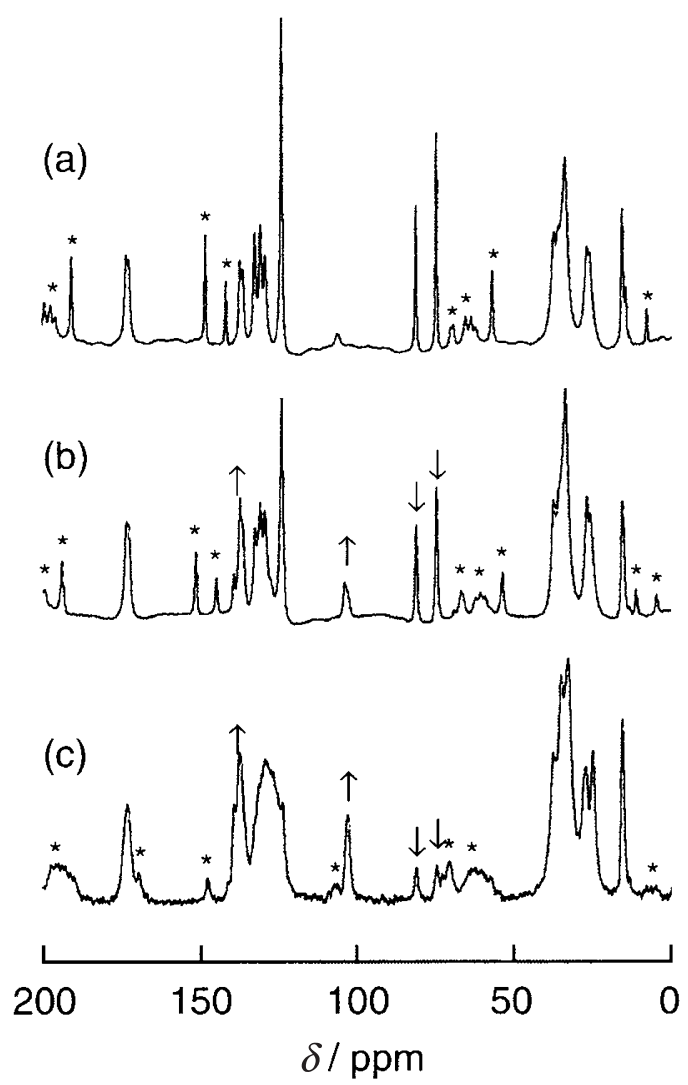

Figure 8. ${ }^{13} \mathrm{C} \mathrm{CP/MAS} \mathrm{spectra} \mathrm{of} \mathrm{7A-10:} \mathrm{(a)} \mathrm{Monomer,} \mathrm{(b)}$ after 250-kGy $\gamma$-ray dose and (c) after 3-MGy $\gamma$-ray dose. Asterisks indicate spinning sidebands.

peak assigned to olefinic carbons in the PDA backbones was expected to appear, the peak intensity seemed to increase. Actually, in dipolar dephasing spectrum, in which the quaternary carbon peaks are intensified, the new olefinic peak at $137 \mathrm{ppm}$ was observed. The stressing point in Figure 8 is that two peaks at around $80 \mathrm{ppm}$ continued to decrease and peaks at $103 \mathrm{ppm}$ and 


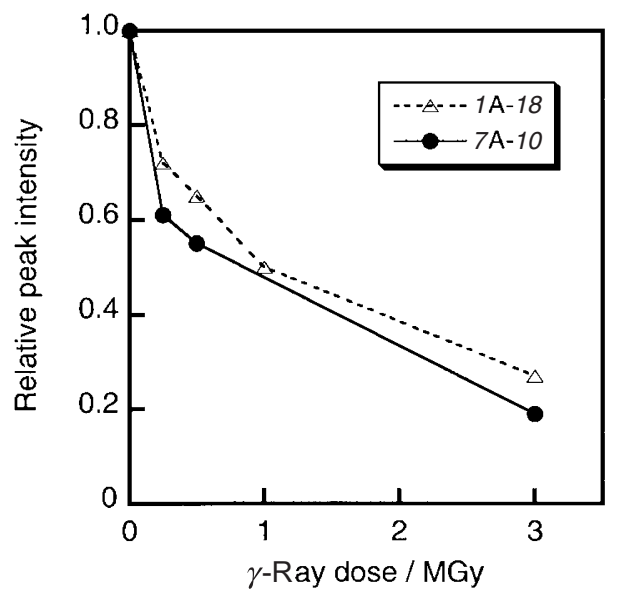

Figure 9. The relationship between $\gamma$-ray dose and the relative ${ }^{13} \mathrm{C}$ peak intensity of the monomer acetylenic carbon at $81 \mathrm{ppm}$. As a reference peak, the carbonyl carbon peak at 173 ppm was selected. Since ${ }^{13} \mathrm{C}$ peak intensities are affected by the relaxation time even in the same experimental conditions and the relaxation time can be varied during solid-state polymerization in the same carbon, it should be noted that this figure shows only the qualitative tendency even though the selected reference peak seemed to be less influenced by the environmental change in the course of polymerization compared with the other carbons.

$137 \mathrm{ppm}$ continued to increase even after the achievement of quantitative polymer yield by $250-\mathrm{kGy} \gamma$-ray dose. This fact indicates that single-chain PDAs have already been produced by $250-\mathrm{kGy} \gamma$-ray dose, and further $\gamma$-ray irradiation stimulated polymerization of the remaining butadiyne moieties to give double-chain PDAs, i.e., ladder-type PDAs. However, ${ }^{13} \mathrm{C}$ peaks originated from unpolymerized butadiyne moieties still remained after $\gamma$-ray irradiation of $3 \mathrm{MGy}$, as shown in Figure 8c, implying partial existence of single-chain PDAs. Difference in polymerization rates between the first and second steps of polymerization are qualitatively understood by change in the ${ }^{13} \mathrm{C}$ peak intensity of the monomer acetylenic carbon as displayed in Figure 9. This clearly shows the reaction rate of the first step almost completed by $250-\mathrm{kGy} \gamma$-ray dose is faster than that of the second step.

In UV-visible diffuse reflectance spectra of $\gamma$-ray irradiated samples with $250-\mathrm{kGy}$ dose, the maximum wavelength for the excitonic band and its phonon sideband were observed at about $615 \mathrm{~nm}$ and about $570 \mathrm{~nm}$, respectively. Although the excitonic maximum wavelength of $m \mathbf{A}-n$ is about $15-\mathrm{nm}$ shorter than that of $\mathbf{N}$ $n$, the excitonic band of $m \mathbf{A}-n$ has shoulder in longer wavelength region at around $640 \mathrm{~nm}$. In order to investigate the developing behavior of the excitonic band, UV-visible diffuse reflectance spectral change of $1 \mathrm{~A}-10$ during UV irradiation was monitored (Figure 10). At first, the shoulder at around $640 \mathrm{~nm}$ was not prominent. However, its growth rate of the intensity gradually in-

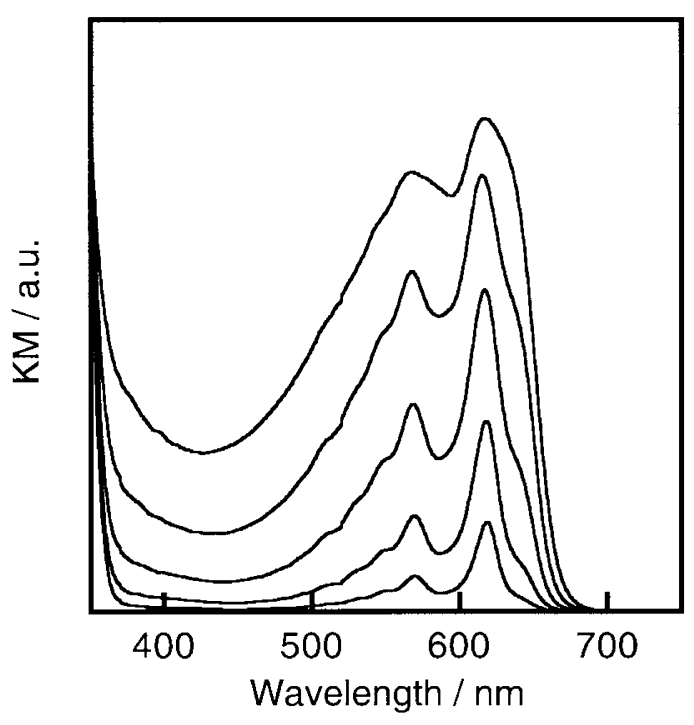

Figure 10. UV-visible diffuse reflectance spectral change of polymers from 1 A-10 depending on UV irradiation time. The curves from the bottom to the top correspond to the spectra obtained after UV irradiation for $1 \mathrm{~min}, 3 \mathrm{~min}, 10 \mathrm{~min}, 40 \mathrm{~min}$, and $4 \mathrm{~h}$, respectively.

creased and the intensities at around $615 \mathrm{~nm}$ and around $640 \mathrm{~nm}$ became similar at the final stage. This result suggests that two types of polymers are produced from the view point of the optical property. As the mechanism to give two types of polymers, the following two reasons were considered: (A) Two different monomer structures in crystals result in two polymer structures, and (B) two different polymer structures are generated in the course of polymerization from single phase of the monomer structure. Between them, the former case (A) can be excluded because solid-state ${ }^{13} \mathrm{C}$ NMR spectrum of the monomer was simple to suggest single phase of its crystal structure as shown above. One of the plausible explanation for the latter reason (B) is that, by formation of the ladder polymer, distortion of the $\pi$ conjugated polymer backbone is reduced and/or the dihedral angle between phenyl rings in the side chains and polymer backbone becomes small to enhance $\pi$ conjugation. When the PDA-base ladder polymer is produced, double rigid backbones in a polymer may enforce to increase planarity of the polymer.

Figure 11 shows the X-Ray diffraction pattern change of $7 \mathbf{A}-10$ depending on increase of $\gamma$-ray dose, as a typical illustration. The crystallinity of $m \mathbf{A}-n$ was generally maintained even after solid-state polymerization till quantitative conversion for the single chainpolymer was achieved. This is due to providing four arrays of intermolecular hydrogen bonding sequences in an $m \mathbf{A}-n$ monomer, and it helps to proceed further polymerization. However, during the procedure to convert into the ladder polymer, crystallinity was deteriorated. This transition of diffraction patterns indicates 
that the second step of polymerization causes relatively large movement of the polymer, which may be related to increase in planarity of the polymer. In order to elucidate the effect of methylene numbers $m$ and $n$ on the molecular alignment of $m \mathbf{A}-n$ in crystals, long-period

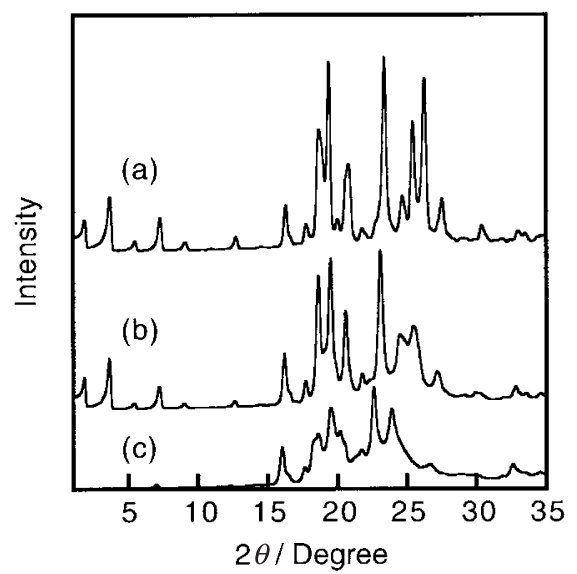

Figure 11. Powder X-Ray diffraction patterns of 7A-10: (a) Monomer and polymers obtained after $\gamma$-ray irradiation with (b) 500-kGy dose and (c) 3-MGy dose, respectively.

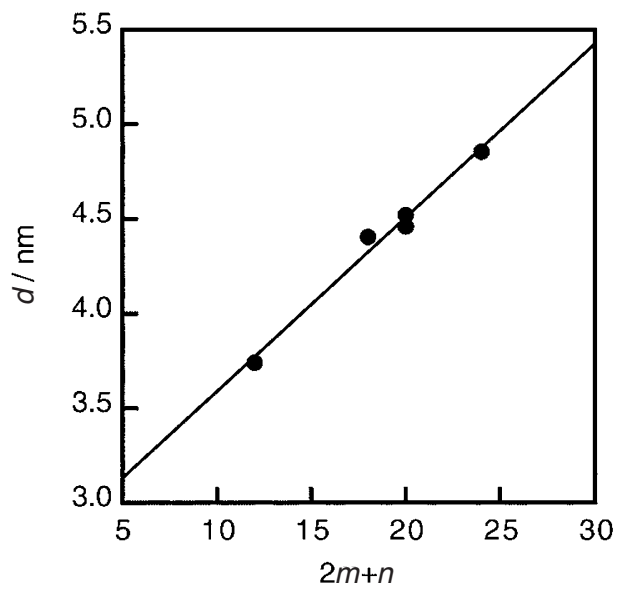

Figure 12. The relationship between number of methylene carbons contained in a monomer $(2 m+n)$ and the long-period spacing (d) in crystals for a series of $m \mathbf{A}-n$ monomers. spacings $(d)$ of $m \mathbf{A}-n$ are plotted against the methylenenumber summation of a monomer, i.e., $2 m+n$, as shown in Figure 12. Since all points are on a same straight line, it was found that this series of $m \mathbf{A}-n$ derivatives have a similar layered structure and inner and outer methylene chains have the same effect for the molecular alignment of $m \mathbf{A}-n$ in crystals.

When the two butadiyne moieties in a monomer polymerize in the solid state as in this study, the possible resulting polymers are not only ladder polymers but also two-dimensional (2D) sheet-type polymers and three-dimensional (3D) crosslinked polymers. However, we think that the obtained polymers from $m \mathbf{A}$ $n$ are ladder polymers because of the following point conducted from the above experimental results. Considering from the position of amide groups attached to $m \mathbf{A}-n$, the most probable molecular alignment is as shown in Figure 13a. This was supported by the X-Ray diffraction data showing their layered structure in crystals. In such molecular alignment, production of $2 \mathrm{D}$ or 3D polymers without serious deterioration of crystallinity should be topochemically excluded.

\section{CONCLUSION}

We synthesized two series of monomers $\mathbf{N}-n$ and $m \mathbf{A}-n$, in which two diphenylbutadiyne moieties are connected by a methylene chain via amido groups. Their solid-state polymerization behaviors were investigated in detail, and they are schematically summarized in Figure 13. In the case of $\mathbf{N}-n$, solid-state polymerization only proceeds in one of two diphenylbutadiyne moieties in a monomer, since atomic movements during polymerization affect to distort the polymerizable stack of the other remaining diphenylbutadiyne. Although diphenylbutadiyne moieties in $\mathbf{N}$ $n$ are fixed by two arrays of intermolecular hydrogen bonding, they are insufficient to keep the polymerizable
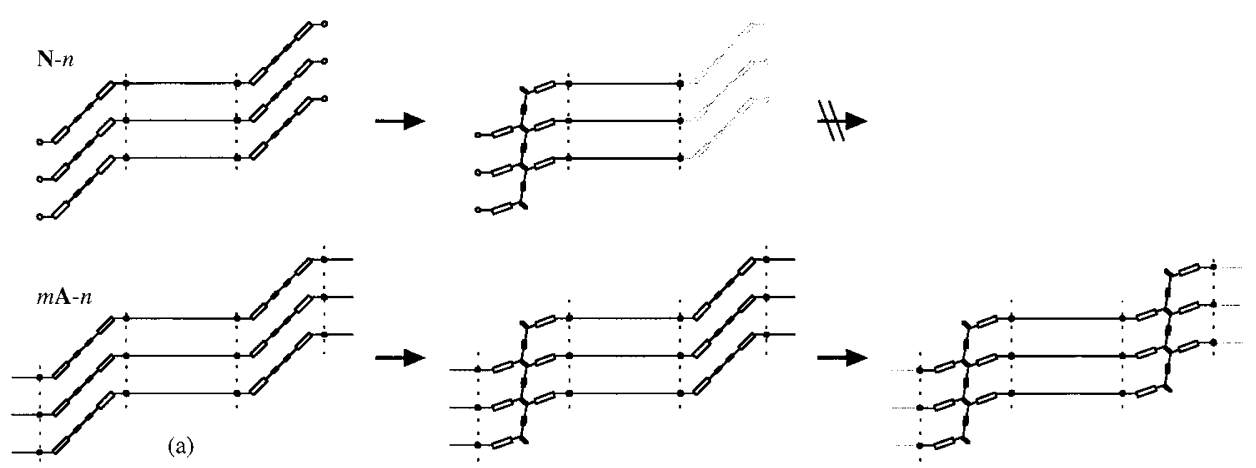

Figure 13. Schematic summary of the solid-state polymerization of $\mathbf{N}-n$ and $m \mathbf{A}-n$. Thin and thick solid lines indicate single bonds including methylene chains and multiple bonds, respectively. Aromatic rings are drown as rectangle. Open and closed circles represent nitro and amido groups, respectively. Dotted lines are for hydrogen bondings. Distorted parts are displayed as gray color. 
stack till all diphenylbutadiyne moieties are converted to PDA. On the other hand, $m \mathbf{A}-n$, which can form four arrays of intermolecular hydrogen bonding on both sides of each diphenylbutadiyne moiety, was found to polymerize at both diphenylbutadiyne moieties to give ladder-type PDA polymers. It was experimentally clarified that synthesis of PDA-based ladder polymers from the monomer functionallized by two diphenylbutadiyne moieties could be achieved if the polymerizable structure was maintained without influence from the atomic movement of polymerized portions. Increase of intermolecular hydrogen bonding was found to be effective for such purpose.

\section{REFERENCES}

1. G. Wegner, Z. Naturforsch., 24, 824 (1969).

2. V. Enckelmann, in "Polydiacetylenes", H.-J. Cantow Ed., Advance in Polymer Science, Springer-Verlag, Berlin, 1984, vol. 63, p 91.

3. H. Bässler, in "Polydiacetylenes", D. Bloor, and R. R. Chance Ed., NATO ASI Ser. E: Appl. Sci., Martinus Nijhoff Publishers, Dordrecht, 1985, vol. 102, p 135.

4. H. Nakanishi, H. Matsuda, and M. Kato, Mol. Cryst. Liq. Cryst., 105, 77 (1984).

5. A. Sarkar, S. Okada, H. Matsuzawa, H. Matsuda, and H. Nakanishi, J. Mater. Chem., 10, 819 (2000).

6. C. Sauteret, J.-P. Hermann, R. Frey, F. Pradère, J. Ducuing, R. H. Baughman, and R. R. Chance, Phys. Rev. Lett., 36, 956 (1976).

7. G. M. Carter, J. V. Hryniewicz, M. K. Thakur, Y. J. Chen, and S. E. Meyler, Appl. Phys. Lett., 48, 998 (1986).

8. T. Hattori and T. Kobayashi, Chem. Phys. Lett., 133, 230 (1987).

9. S. Molyneux, H. Matsuda, A. K. Kar, B. S. Wherrett, S. Okada, and H. Nakanishi, Nonlinear Opt., 4, 299 (1993).

10. S. Etemad, G. L. Baker, and Z. G. Soos, in "Molecular Nonlinear Optics Materials, Physics, and Devices", J. Zyss Ed., Academic Press Inc., Boston, CT, 1994, p 433.

11. G. I. Stegeman, in "Nonlinear Optics of Organic Molecules and Polymers", H. S. Nalwa and S. Miyata Ed., CRC Press, Boca Raton, 1997, p 799.

12. M. Bakarezos, M. A. Camacho, I. J. Blewett, A. K. Kar, B. S. Wherrett, H. Matsuda, T. Fukuda, S. Yamada, R. RangelRojo, H. Katagi, H. Kasai, S. Okada, and H. Nakanishi, Electron. Lett., 35, 1078 (1999).

13. B. J. Orchard and S. K. Tripathy, Macromolecules, 19, 1844 (1986)

14. S. B. Clough, S. Kumar, X. F. Sun, S. Tripathy, H. Matsuda, H. Nakanishi, S. Okada, and M. Kato, in "Nonlinear Optics of Organics and Semiconductors", T. Kobayashi Ed., Springer Proceeding in Physics, Springer-Verlag, Berlin, 1989, vol. 36, p 149.

15. H. Matsuda, H. Nakanishi, T. Hosomi, and M. Kato, Macromolecules, 21, 1238 (1988).

16. H. Nakanishi, H. Matsuda, S. Okada, and M. Kato, in "Frontiers of Macromolecular Science", T. Saegusa, T. Higashimura, and A. Abe Ed., Blackwell Scientific Publications Ltd., Oxford, 1989, p 469.

17. H. Nakanishi, H. Matsuda, S. Okada, and M. Kato, Polym. Adv. Technol., 1, 75 (1990).

18. S. Okada, M. Ohsugi, A. Masaki, H. Matsuda, S. Takaragi, and H. Nakanishi, Mol. Cryst. Liq. Cryst., 183, 81 (1990).

19. A. Sarkar, S. Okada, H. Nakanishi, and H. Matsuda, Macromolecules, 31, 9174 (1998).

20. S. Okada, K. Hayamizu, H. Matsuda, A. Masaki, and H. Nakanishi, Bull. Chem. Soc. Jpn., 64, 857 (1991).

21. S. Okada, T. Doi, A. Mito, K. Hayamizu, A. Ticktin, H. Matsuda, N. Kikuchi, A. Masaki, N. Minami, K.-H. Haas, and H. Nakanishi, Nonlinear Opt., 8, 121 (1994).

22. S. Okada, K. Hayamizu, H. Matsuda, A. Masaki, N. Minami, and H. Nakanishi, Macromolecules, 27, 6259 (1994).

23. H. Matsuzawa, S. Okada, H. Matsuda, and H. Nakanishi, in "Photopolymer Device Physics, Chemistry, and Applications III", R. A. Lessard Ed., Proc. SPIE, SPIE, Bellingham, 1996, vol. 2851, p 14.

24. S. Okada, H. Nakanishi, H. Matsuzawa, H. Katagi, T. Oshikiri, H. Kasai, A. Sarkar, H. Oikawa, R. Rangel-Rojo, T. Fukuda, and H. Matsuda, in "Organic Nonlinear Optical Materials”, M. Eich and M. G. Kuzyk Ed., Proc. SPIE, SPIE, Bellingham, 1999, vol. 3796, p 76.

25. H. Matsuzawa, S. Okada, A. Sarkar, H. Matsuda, and H. Nakanishi, J. Polym. Sci., Part A: Polym. Chem., 37, 3537 (1999).

26. H. Matsuzawa, S. Okada, A. Sarkar, H. Matsuda, and H. Nakanishi, Polym. J., 33, 182 (2001).

27. S. Nagahama and A. Matsumoto, J. Am. Chem. Soc., 123, 12176 (2001).

28. H. Nakanishi, H. Matsuda, S. Takaragi, S. Okada, and M. Kato, in "Nonlinear Optical Properties of Materials", 1988 Technical Digest Ser., Optical Society of America, Washington, D.C., 1988, vol. 9, p 182.

29. G. Wegner, J. Polym. Sci., Polym. Lett. Ed., 9, 133 (1971).

30. H. Nakanishi, H. Matsuda, M. Kato, C. R. Theocharis, and W. Jones, J. Chem. Soc., Parkin. Trans. 2, 1965 (1986).

31. S. Takahashi, Y. Kuroyama, K. Sonogashira, and N. Hagihara, Synthesis, 1980, 627.

32. W. Chodkiewicz, J. S. Alhuwalia, P. Cadiot, and A. Willemart, Compt. Rend., 245, 322 (1957).

33. A. S. Hay, J. Org. Chem., 27, 3320 (1962).

34. H. Tachibana, R. Kumai, N. Hosaka, and Y. Tokura, Chem. Mater., 13, 155 (2001).

35. T. Kurihara, M. Fujiki, F. Ebisawa, and H. Tabei, Polym. Prepr. Jpn., 33, 1211 (1984).

36. S. Okada, H. Matsuda, M. Otsuka, H. Nakanishi, and M. Kato, Bull. Chem. Soc. Jpn., 67, 483 (1994). 